\title{
Effect of Binder Conformity on the Electrochemical Behavior of Graphite Anodes with Different Particle Shapes
}

\author{
Rahim Shah 1,2, Naveed Alam ${ }^{1,2}$, Amir A. Razzaq ${ }^{1,2}$, YANG Cheng ${ }^{1,2}$, CHEN Yujie ${ }^{1,2}$, HU Jiapeng ${ }^{1,2}$, \\ ZHAO Xiaohui ${ }^{1,2, *}$, PENG Yang ${ }^{1,2}$, DENG Zhao ${ }^{1,2,{ }^{*}}$ \\ ${ }^{1}$ Soochow Institute for Energy and Materials Innovations, College of Energy, Soochow University, Suzhou 215006, Jiangsu \\ Province, P. R. China. \\ ${ }^{2}$ Provincial Key Laboratory for Advanced Carbon Materials and Wearable Energy Technologies, Soochow University, Suzhou \\ 215006, Jiangsu Province, P. R. China.
}

\begin{abstract}
As an important component in electrodes, the choice of an appropriate binder is significant when fabricating lithium-ion batteries (LIBs) with good cycle stability and rate capability, which are used in numerous applications, especially portable electronics and eco-friendly electric vehicles (EVs). Semi-crystalline poly(vinylidene

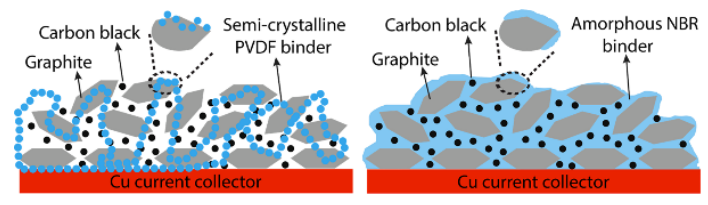
fluoride) (PVDF), which is a traditional and widely used binder, cannot efficiently accommodate the volume changes observed in the anode during the charge-discharge process while binding all the components in the electrode together, which results in increased internal cell resistance, detachment of the electrode components, and capacity fading. Herein, we have investigated a highly polar and elastomeric polyacrylonitrile-butadiene (NBR) rubber for use as a binder in LIBs, which can accommodate graphite particles of different shapes compared to semi-crystalline PVDF. Prior to our electrochemical tests, NBR was analyzed using thermogravimetric analysis (TGA) and X-ray diffraction (XRD), showing good thermal stability and an amorphous morphology. NBR is more conformable to irregular surfaces, which results in the formation of a homogeneous passivation layer on both spherical and flaky graphite particles to effectively suppress any electrolyte side reactions, further allowing more uniform and fast Li ion diffusion at the electrolyte/electrolyte interface. As a result, the electrochemical performance of both spherical and flaky shape graphite electrodes was significantly improved in terms of their first cycle Coulombic efficiency (CE) and cycle stability. With comparative specific capacity, the first cycle CE of the NBR-based spherical and flaky graphite electrodes were $87.0 \%$ and $85.5 \%$, compared to $85.3 \%$ and $82.6 \%$ observed for their corresponding PVDF-based electrodes, respectively. After 1000 discharge-charge cycles at $1 C$, the capacity retention of the NBR-based graphite electrodes was significantly higher than that of PVDF-based electrodes. This was attributed to the good stability of the solid electrolyte interphase (SEI) formed on the graphite electrodes and the high stretching ability of the elastomeric NBR binder, which help to accommodate the repeated volume fluctuation of graphite observed during long-term charge-discharge cycling. Electrochemical impedance spectroscopy (EIS) and microscopic analysis (SEM and TEM) were carried out to investigate the formation and evolution of the SEI layers formed on the spherical and flaky graphite electrodes. The results show that thin, homogeneous, and stable SEl layers are formed on the surface of both spherical and flaky graphite electrodes prepared using the NBR binder. When compared to the PVDFbased graphite electrodes, the graphite electrodes constructed using NBR showed decreased resistance in the SEI layer and faster charge transfer, thus enhancing the electrode kinetics for $\mathrm{Li}$ ion intercalation/deintercalation. Our study shows that the electrochemical performance of spherical and flaky graphite electrodes prepared using the NBR binder is significantly improved, demonstrating that NBR is a promising binder for these electrodes in LIBs.
\end{abstract}

Received: March 26, 2019; Revised: April 30, 2019; Accepted: May 13, 2019; Published online: May 20, 2019.

*Corresponding authors. Emails: zhaoxh@suda.edu.cn (Z.X.); zdeng@suda.edu.cn (D.Z.).

The project was supported by the National Natural Science Foundation of China (21701118, 21805201), the Natural Science Foundation of Jiangsu Province, China (BK20161209, BK20160323, BK20170341), the Postdoctoral Science Foundation of China (2017M611899, 2018T110544) and the Key Technology Initiative of Suzhou Municipal Science and Technology Bureau, China (SYG201748).

国家自然科学基金(21701118, 21805201), 江苏省自然科学基金(BK20161209, BK20160323, BK20170341), 中国博士后科学基金(2017M611899, 2018T110544), 苏州市产业技术创新专项(前瞻性应用研究) (SYG201748)资助项目

(C) Editorial office of Acta Physico-Chimica Sinica 
Key Words: Binder; Polyacrylonitrile-butadiene; Graphite anode; Electrochemical performance; Lithium ion battery

\title{
粘结剂对形貌各异的石墨负极电化学性能的影响
}

\author{
Rahim Shah ${ }^{1,2}$, Naveed Alam ${ }^{1,2}$, Amir A. Razzaq ${ }^{1,2}$ ， 杨成 ${ }^{1,2}$ ， 陈宇杰 ${ }^{1,2}$ ，胡加鹏 ${ }^{1,2}$, \\ 赵晓辉 $1,2, *$, 彭扬 ${ }^{1,2}$, 邓昭 $1,2, *$ \\ 1 苏州大学能源与材料创新研究院, 能源学院, 江苏苏州 215006 \\ 2 江苏省先进碳材料与可穿戴能源技术重点实验室，江苏苏州 215006
}

\begin{abstract}
摘要: 本文通过不同形貌的石墨材料, 研究了聚丙烯腈-丁二烯(NBR)作为锂离子电池粘结剂的电化学性能, 并与商业化粘结 剂聚偏氟乙烯(PVDF)进行了对比。由于NBR无定形的晶体结构和连续性的特点, 使其能够更好的粘结在活性材料表面, 在 球型和片状石墨表面都能形成均一的具有抑制副反应和提高锂离子传输能力的保护层。实验证明, 片层状石墨在以PVDF作 粘结剂时, 电化学性能较差。然而, 以NBR作为粘结剂时, 球型和片状的石墨材料在库伦效率、循环稳定性和传输动力学上 都有明显的提升。此项研究证实了粘结剂和活性材料的一致性对于提高锂离子电池电化学性能的重要性。
\end{abstract}

关键词: 粘结剂; 聚丙烯腈-丁二烯; 石墨负极; 电化学性能; 锂离子电池 中图分类号: 0646

\section{Introduction}

Lithium ion batteries (LIBs) have been increasingly used as the power source for portable electronic devices and shown significant perspective for automobiles and smart grids ${ }^{1}$. While their performance is largely determined by the active materials for Li storage and conversion, other electrode components such as the conductive agents and binders are vitally important to achieve high Coloumbic efficiency and rate capability ${ }^{2}$. In particular, the binder, by coalescing the active material and conductive additive together and sticking them to the current collector, and are of great importance for the interfacial properties and structural stabilities. Synergies among these electrode components enables to further leap the electrochemical performance of LIBs through a more coherent ion diffusion, electron transfer and stabilized interfaces in the electrodes.

In last two decade poly(vinylidene fluoride) (PVDF) has been one of the most widely used binders for both the anode and cathode of commercial LIBs due to its excellent electrochemical and thermal stability, providing good adhesive strength to bind the interior electrode components, glue the electrode film to the current collector ${ }^{3}$. However, PVDF binder is readily swollen, gelled or dissolved by organic electrolytes, forming nonconductive and viscous interfacial layers, which result in an increases the internal cell resistance and detachment of electrode components that lead to capacity fading and shortened lifetime ${ }^{4,5}$. Beside this, the fluorinated PVDF might also react with Li ions, especially at elevated temperature, to disrupt the solid electrolyte interface (SEI) on the electrode, which may accelerate $\mathrm{Li}$ dendrite formation and further trigger thermal runway ${ }^{6}$. Therefore, it is essential to develop alternative binders that are non-fluorinated, cheaper and essentially conductive to build up effective paths for both charge transfer and $\mathrm{Li}^{+}$diffusion. For that, a number of binders such as poly(vinyl alcohol) ${ }^{7}$, polystyrene-butadiene (SBR) ${ }^{8}$, poly(methacrylic acid) ${ }^{9}$, sodium carboxy methyl cellulose (CMC) ${ }^{10}$, acrylonitrile-grafted poly(vinyl alcohol) copolymer ${ }^{11}$, polyacylic acide ${ }^{12}$, arboxymethyl fenugreek gum ${ }^{13}$, galactomannan gum ${ }^{14}, \beta$ cyclodextrin ${ }^{15}$, alginate ${ }^{16}$, polyethylene imine ${ }^{17}$, polyimide ${ }^{18}$, and lignine ${ }^{19}$, etc. have been reported with improvements in one or other aspects. Also, it has been proved that different cathode or anode materials might need specific binders to obtain the optimal performance based on their composition or surface properties. For example, SBR has been widely used as the Sibased anode binder due to their elastomeric properties and high viscosity 7a,20. Nevertheless, similar correlation between the binder property and shape of active component has been seldom studied.

In this paper, polyacrylonitrile-butadiene (NBR) as a nonfluorinated polymer, is adopted as the electrode binder for graphite anodes. NBR is an elastomer mainly composed of copolymerized butadiene and acrylonitrile units and has been widely used in many fields including fuel and oil handling hose, grommets, disposable lab, and examination gloves and so on. However, to the best of our knowledge, it has been barely adopted as the binder for LIBs. In this work, we intend to compare the NBR and PVDF as the anode binders in response to different shapes of graphite particles, in terms of SEI formation, first Coulombic efficiency, and long-term cycling performance. Compared to PVDF, NBR demonstrated a better conformity to the irregular graphite shape, not only serving as a good binder, but also a passivation layer on the graphite surface to impart great interfacial stability, ionic conductivity, and Coulombic efficiency.

\section{Experimental method}

\subsection{Preparation of electrodes}


Two types of graphite powder with different morphology, spherical graphite (S-graphite, BTR New Energy Material) of 20-30 $\mu \mathrm{m}$, and flaky graphite (F-graphite, Macklin Inc.) of 10$20 \mu \mathrm{m}$ were used as the active materials to investigate the performance of NBR (XNBRL-830, Shanghai Jenlan) and PVDF (Nippon Zeon) as the polymer binder. Graphite electrode slurries were prepared by dispersing the mixture of graphite powders (85\%, mass fraction), carbon black (Macklin Inc., 5\%) and binder (10\%) in 1-methyl-2-pyrrolidone (NMP) solvent using low speed ball milling to homogenized the mixture at rate of $600 \mathrm{r} \cdot \mathrm{min}^{-1}$ for $1 \mathrm{~h}$. The slurries were then coated onto copper foil using a doctor blade. Through varying the height of the blade, all the electrodes laminate were controlled to have approximately the same mass loading of active material (3.5 $\mathrm{mg} \cdot \mathrm{cm}^{-2}$ ). The obtained electrodes were dried in vacuum oven at $120{ }^{\circ} \mathrm{C}$ overnight to completely remove the NMP solvent and then directly punched into round slices of $c a .1 .33 \mathrm{~cm}^{2}$. The graphite electrodes with PVDF and NBR binders are thus designated as S-graphite-PVDF, S-graphite-NBR, F-graphitePVDF, and F-graphite-NBR, respectively.

\subsection{Material characterization}

Morphological characterizations of the graphite powders and graphite electrodes were carried out by high-resolution transmission electron microscope (TEM, FEI TECNAI F20 200 $\mathrm{kV}$ ) and scanning electron microscopy (FE-SEM, Hitachi SU8010 FE-SEM). Thermogravometric analysis (TGA, SDT 2960) of the binders were taken to determine their thermal stability up to $600{ }^{\circ} \mathrm{C}$ at a heating rate of $10{ }^{\circ} \mathrm{C} \cdot \mathrm{min}^{-1}$ in argon, X-ray diffraction (XRD, Bruker D8 Advance) was used to determine the crystalline structure of both NBR and PVDF powders.

\subsection{Electrochemical measurements}

Electrochemical performances of different graphite electrodes were evaluated in CR2032 coin-type cells, which were assembled in an argon-filled glove box $\left(<10^{-7}\right.$ of water and oxygen) with lithium metal foil as the counter electrode. 1 $\mathrm{mol} \cdot \mathrm{L}^{-1}$ lithium hexaflurophosphate $\left(\mathrm{LiPF}_{6}\right)$ in a $1: 1: 1$ volume ratio of ethylene carbonate/diethyl carbonate/dimethyl carbonate (EC/DEC/DMC, DoDoChem) was used as the electrolyte and
Celgard $^{\circledR} 2500$ was used as a separator. The cells were galvanostatically charged-discharged at different C-rates between the voltage window of $0.01-2.0 \mathrm{~V}$ vs. $\mathrm{Li}^{-\mathrm{Li}^{+}}$at $30{ }^{\circ} \mathrm{C}$ using the LANHE battery testing system (Wuhan LAND electronics Co., China). A CHI 660E electrochemical workstation was used to record cyclic voltammogram (CV) at a scan rate of $0.05 \mathrm{mV} \cdot \mathrm{s}^{-1}$ within $0.01-2 \mathrm{~V}$ and electrochemical impendence spectra (EIS) at the frequency range of $100 \mathrm{kHz}-10$ $\mathrm{mHz}$ at an amplitude of $5 \mathrm{mV}$.

\section{Results and discussion}

The repeating units of NBR and PVDF are illustrated in Fig. 1a, showing the block copolymer structure of NBR and the fluorine-containing polyvinyl backbone of PVDF. The thermal stabilities of both binders were examined by TGA and the corresponding plots of weight loss $v$ s temperature are shown in Fig. 1b. High thermal stability was observed for both the PVDF and NBR binders, showing an onset decomposition temperature at about $400{ }^{\circ} \mathrm{C}$, and rapid weight loss at $450{ }^{\circ} \mathrm{C}$ for about $60 \%$. For the NBR binder, additional decomposition stages can be observed until $600{ }^{\circ} \mathrm{C}$ due to its hydrocarbon nature. We note NBR binder also has low glass temperature $\left(T_{\mathrm{g}}\right)$ down to $-40{ }^{\circ} \mathrm{C}$ dependent on the nitrile content, allowing a wide range of operational temperature for the fabricated $\mathrm{LIBs}^{21}$. XRD analysis reveals that NBR, with a broad peak at $19^{\circ}$, has lower crystallinity than PVDF binder does, while PVDF exhibits semicrystallinity with sharp diffraction peaks respectively at $18.3^{\circ}$, $19.9^{\circ}, 26.4^{\circ}, 33^{\circ}, 35.9^{\circ}$ and $38.4^{\circ}$ (Fig. 1c). While SEM images of PVDF reveal a particulate shape, NBR displays as coherent rubber films shed on surface (Fig. 1d, e). The crystallographic and morphological differences between NBR and PVDF may strongly influence their binding behaviors and morphologies in the prepared electrodes. Because of the semi-crystalline structure of the PVDF binder, one can expect a discrete coating when it binds to graphite, exposing more underlying graphite surfaces ${ }^{22}$. Thus, it is likely the decomposition of electrolyte to form SEI at the graphite surface bond with PVDF can be accelerated but the surface becomes less stable due to the lack of

(a)
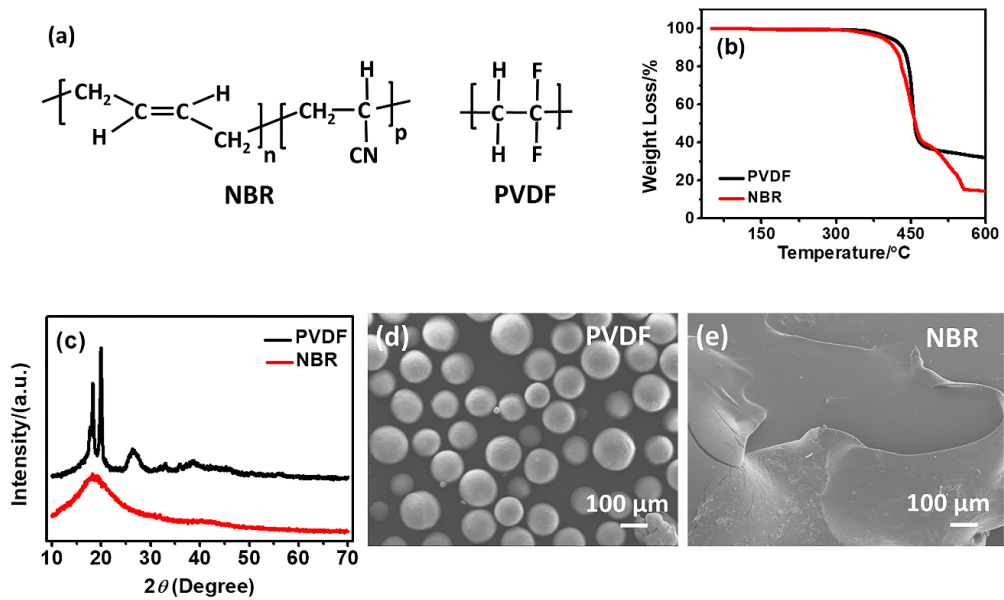

Fig. 1 (a) Molecular structures of PVDF and NBR, (b) TGA, (c) XRD, and (d, e) FE-SEM images of binders. 
passivation. By contrast, the NBR binder forms a more homogeneous coating on the graphite surface, well shielding it from direct contact with electrolyte. The schematic diagrams of the proposed binding mechanism for PVDF and NBR are illustrated in Fig. 2.

Two different shapes of graphite, i.e. spherical and flaky, were used as active materials. Fig $3 \mathrm{a}, \mathrm{b}$ show the comparison of TEM images of both graphite samples. A relatively round contour with little crystalline planes is seen for the spherical graphite, most likely due to the shaping treatment in production, resulting in low-curvature surfaces (Fig. 3a). In contrast, the flaky graphite particles exhibit sharper edges with high-crystallinity thin sheets clearly visible by TEM, and thus present more high-curvature features (Fig. 3b). As a result of the microstructural curvature, binders with different rigidity and morphology should conform differently to the graphite surfaces. Fig $3 \mathrm{c}-\mathrm{f}$ display the SEM images taken on the graphite electrodes with different particle shapes and binders, showing similar electrode morphology with homogeneously dispersed conductive additive (Super P) ${ }^{23,24 a}$. This suggests the variation in electrochemical properties among these graphite electrodes, if there is, should be mainly ascribed to the microscopic interfacial structure as depicted in Fig. 2, instead of the bulk electrode structure.

The electrochemical performance of the graphite electrodes in half cells $v s \mathrm{Li} / \mathrm{Li}^{+}$were evaluated by $\mathrm{CV}$ and galvanostatic charge-discharge tests. Fig. 4 shows the first three consecutive $\mathrm{CV}$ curves for all graphite electrodes at a scan rate of 0.05 $\mathrm{mV} \cdot \mathrm{s}^{-1}$, in which the differences mainly lie in the following facts. First, a small irreversible reduction peak at around $0.75 \mathrm{~V}$ related to the formation of solid electrolyte interface (SEI) layer is clearly seen in the first cathodic scan of all graphite electrodes, with those associated with flaky graphite slightly higher. This indicates more electroactive surface are exposed to the electrolyte on the flaky graphite. Meanwhile, in comparison to PVDF, the SEI peaks are significantly suppressed by the NBR binder on either type of the graphite, suggesting improved passivation of the graphite surface by NBR, due to its coherent morphology and better conformity to the graphite shape. These SEI peaks were observed completely disappeared in the subsequent cycles, affirming good SEI stability on the graphite surface. The convoluted anodic peaks are ascribed to the overlap of different delithiation stages, and all peaks are wellsuperimposed in the sequential scans, predicting a good stability and reversibility in prolonged cycles ${ }^{25}$. Secondly, all graphite electrodes present sharp reduction peaks below $0.25 \mathrm{~V}$ corresponding to the intercalation of $\mathrm{Li}^{+}$into graphite, and those with NBR are slightly higher and sharper, suggesting that the overall electrode kinetics for $\mathrm{Li}^{+}$insertion/de-insertion are faster. In addition, there are no unexpected peaks observed in the potential range, proving that NBR is electrochemically durable
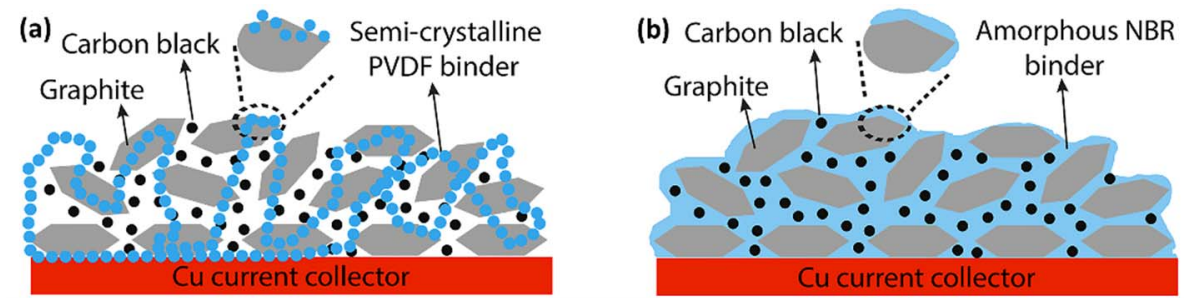

Fig. 2 Schematic representation of the binding morphologies of graphite electrodes with (a) semi-crystalline PVDF binder and (b) amorphous NBR binder.
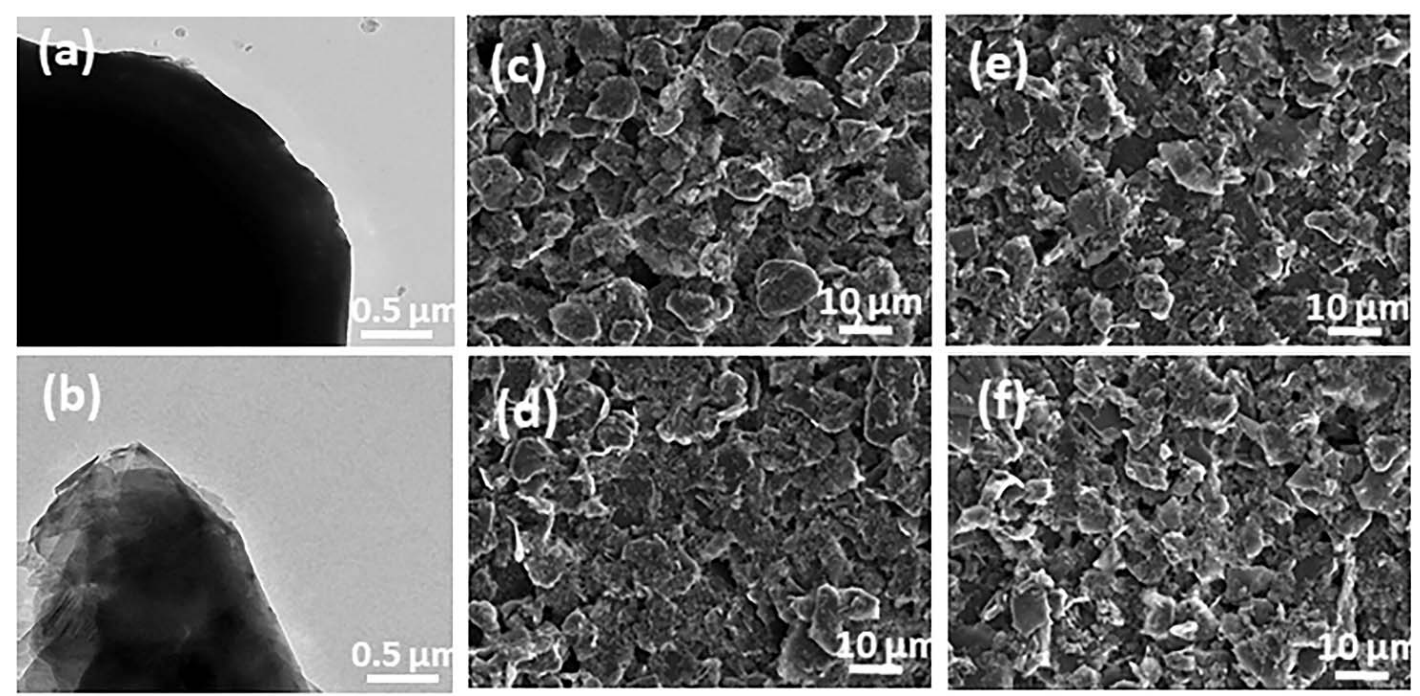

Fig. 3 TEM images of the (a) spherical and (b) flaky graphite particles. FE-SEM images of graphite electrodes, (c) S-graphite-PVDF, (d) S-graphite-NBR, (e) F-graphite-PVDF and (f) F-graphite-NBR. 

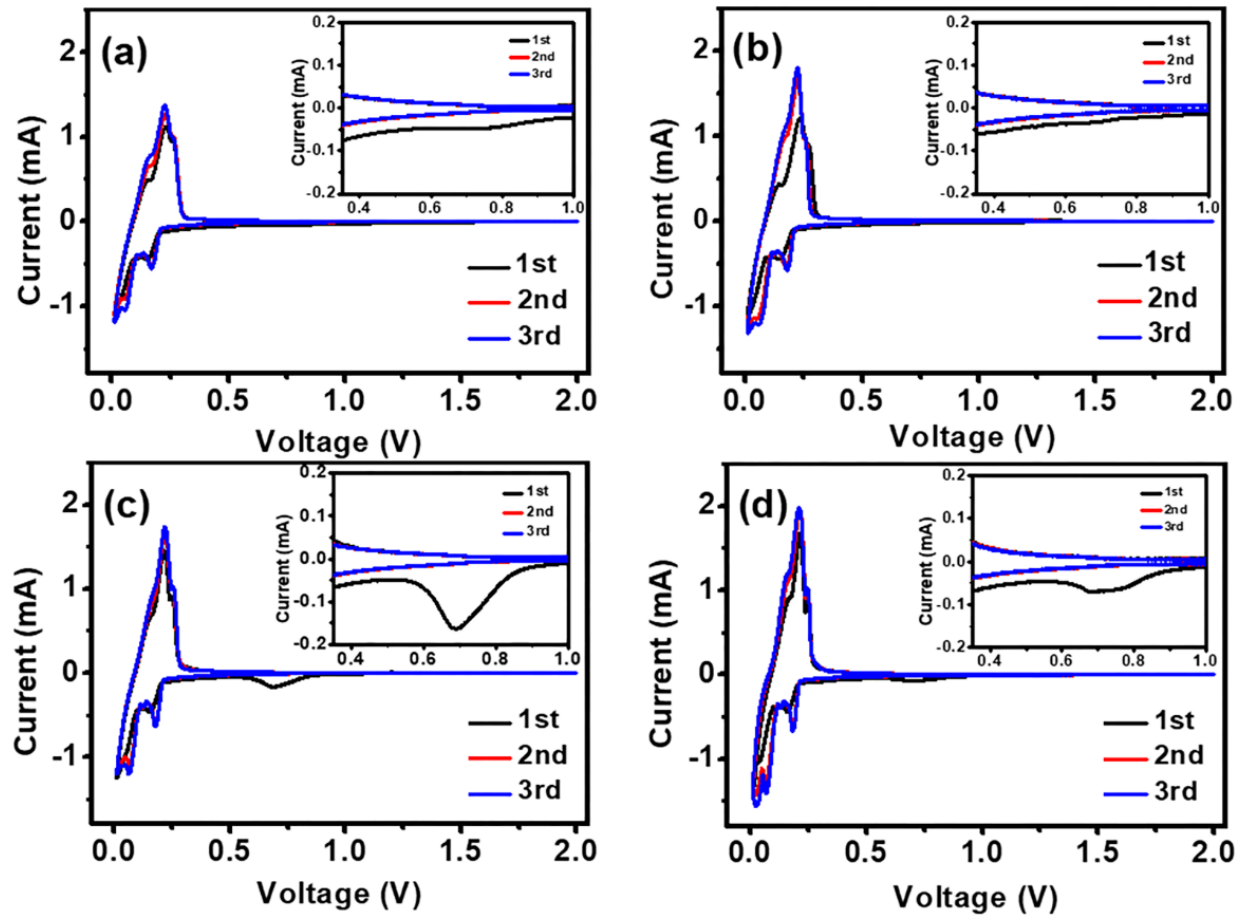

Fig. 4 Cyclic voltammograms of the (a) S-graphite-PVDF, (b) S-graphite-NBR, (c) F-graphite-PVDF, and (d) F-graphite-NBR electrodes.

in the working window. Thirdly, the oxidation and reduction peaks of the graphite electrodes using NBR binder appear shaper than those of the PVDF binder, illustrates that NBR based binder electrodes have better kinetics characteristics. This may be caused by numerous polar nitrile groups in the polymer chains, which contribute to the $\mathrm{Li}^{+}$movement ${ }^{24 \mathrm{~b}}$.

The first discharge-charge curves of all graphite electrodes with the PVDF and NBR binders are shown in Fig. 5a with similar discharge capacities over $400 \mathrm{mAh} \cdot \mathrm{g}^{-1}$. The plateaus in the first discharge at around $0.75 \mathrm{~V}$ are related to the irreversible capacity loss due to the formation of SEI layer and other side reactions of the electrolyte. Again, the electrodes with NBR exhibit lower irreversible capacity due to better passivation of graphite surface, effectively alleviating the electrolyte decomposition ${ }^{26}$. The first-cycle Coulombic efficiencies (C.E) for the S-graphite-PVDF, S-graphite-NBR, F-graphite-PVDF, Fgraphite-NBR electrodes are $85.3 \%, 87.0 \%, 82.6 \%$ and $85.5 \%$,

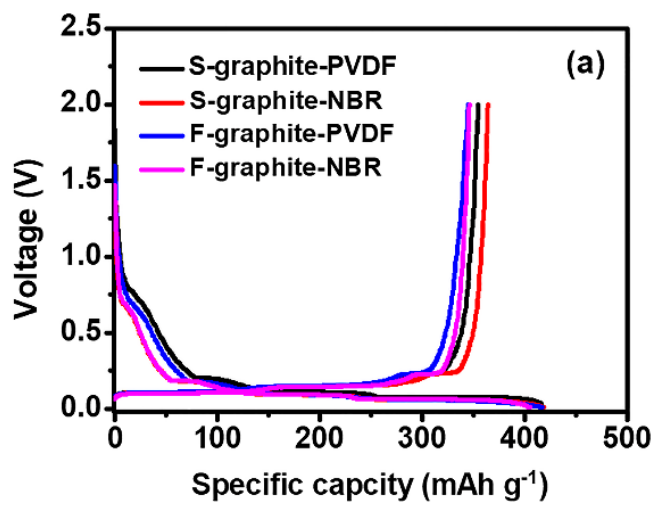

respectively, with the lowest observed for F-graphite-PVDF. Both electrodes of spherical and flaky graphite with the NBR binder delivered high initial C.E, which can be attributed to the enhanced $\mathrm{Li}^{+}$conduction within the polymeric network, in contrast to PVDF and the SEI formed by electrolyte decomposition. It should be noted that the initial C.E of the graphite electrode can also be improve by using electrolyte additives ${ }^{27}$. In the present study no additive has been used in the electrolytes and thus the discrepancy in C.E is mainly from the difference in binders and graphite shapes. Furthermore, to determine the reversible capacities for all graphite electrodes with both NBR and PVDF binders, we evaluated the actual C.E of all four electrodes by dividing the observed capacity from the first cycle into two segments: discharging capacity corresponds to irreversible reaction $\left(Q_{\mathrm{d}}^{\text {irr }}\right)$ and discharging capacity related to $\mathrm{Li}^{+}$intercalation $\left(Q_{\mathrm{d}}^{\mathrm{r}}\right)$ as shown in Fig. 5b. The actual C.E, which excludes the capacity from side reaction, is then calculated as

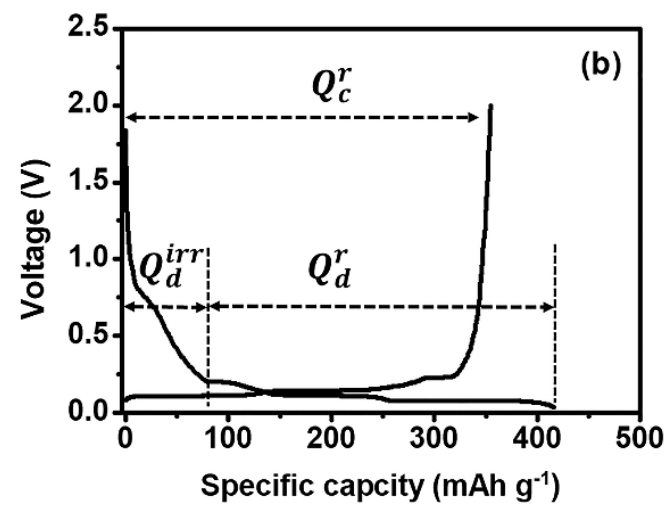

Fig. 5 (a) The first charge-discharge profiles of the S-graphite and F-graphite with PVDF and NBR binder in the potential range of 0.01-2 V vs $\mathrm{Li} / \mathrm{Li}^{+}$at $0.2 C$. (b) Typical first charge-discharge curve of S-graphite-PVDF electrode. 
$Q_{\mathrm{c}}^{\mathrm{r}} / Q_{\mathrm{d}}^{\mathrm{r}}$, where $Q_{\mathrm{c}}^{\mathrm{r}}$ is the charging capacity of the first cycle. In this way, the reversible C.E and the SEI contribution can be calculated and are tabulated in Table 1 together with the overall C.E of the first cycle. Note that the reversible C.E of S-graphitePVDF and F-graphite-PVDF are still lower even after the irreversible capacities are excluded. Meanwhile, F-graphitePVDF shows the highest irreversible capacity (SEI contribution), corroborating the view that PVDF has poor conformity to the high-curvature surface of flaky graphite, exposing more graphite surface for electrolytic SEI formation.

The cycle stability of all graphite electrodes with PVDF and NBR binders was investigated as shown in Fig. 6a-d. At a low $C$-rate of $0.2 C$ all graphite electrodes exhibit stable cyclic performance up to 100 cycles (Fig 6a, b). Notably, while the Sgraphite electrode with PVDF exhibits similar cycling behavior to that of S-graphite electrode with NBR, the flaky graphite bond with PVDF shows a slightly inferior performance to its NBR counterpart. At higher $C$-rates, this discrepancy is further aggrandized. As shown in Fig. 6c and d, both graphite electrodes with the NBR binder demonstrate ultra-stable performance for a long life-span of more than 1000 cycles. By contrast, the PVDF- based electrodes exhibit serious capacity fading after a few hundreds of cycles with the worst seen for F-graphite-PVDF, which only lasts tens of cycles before its capacity starts to fade. The excellent cycling stabilities of the NBR-based electrodes can be mainly ascribed to the following reasons: first, the uniform distribution of the coherent polymeric binder on both the edges and basal planes of the graphite powder can effectively passivate the graphite surface, significantly improving the compatibility of the electrode with electrolyte; second, the strong binding strength of the rubbery polymer coalesce the particles tightly and bind the composite firmly to the current collector, particularly beneficial for the structural stability of the electrode. Third, the relatively high conductivity of the acrylonitrilebutadiene polymer chain, in comparison to the polyvinyl chain of PVDF, facilitate the charge transportation, especially at high charging-discharging rate. Lastly and more importantly, the stretchable nature of the elastomeric NBR binder helps overcome the repeated volume fluctuation of graphite in long term cycles. Such a high cycling stability at high chargedischarge rate observed on NBR is significantly better than previously reported graphite based anode materials as depicted

Table 1 C.E analysis of the initial charge-discharge cycle of S-graphite-PVDF, S-graphite-NBR, F-graphite-PVDF, and F-graphite-NBR electrodes.

\begin{tabular}{|c|c|c|c|c|}
\hline Electrode & S-graphite-PVDF & S-graphite-NBR & F-graphite-PVDF & F-graphite-NBR \\
\hline First-cycle C.E & $85.3 \%$ & $87.0 \%$ & $82.6 \%$ & $85.5 \%$ \\
\hline Reversible C.E & $95.6 \%$ & $99.2 \%$ & $98.5 \%$ & $99.5 \%$ \\
\hline SEI contribution & $10.3 \%$ & $12.2 \%$ & $15.9 \%$ & $14.0 \%$ \\
\hline
\end{tabular}
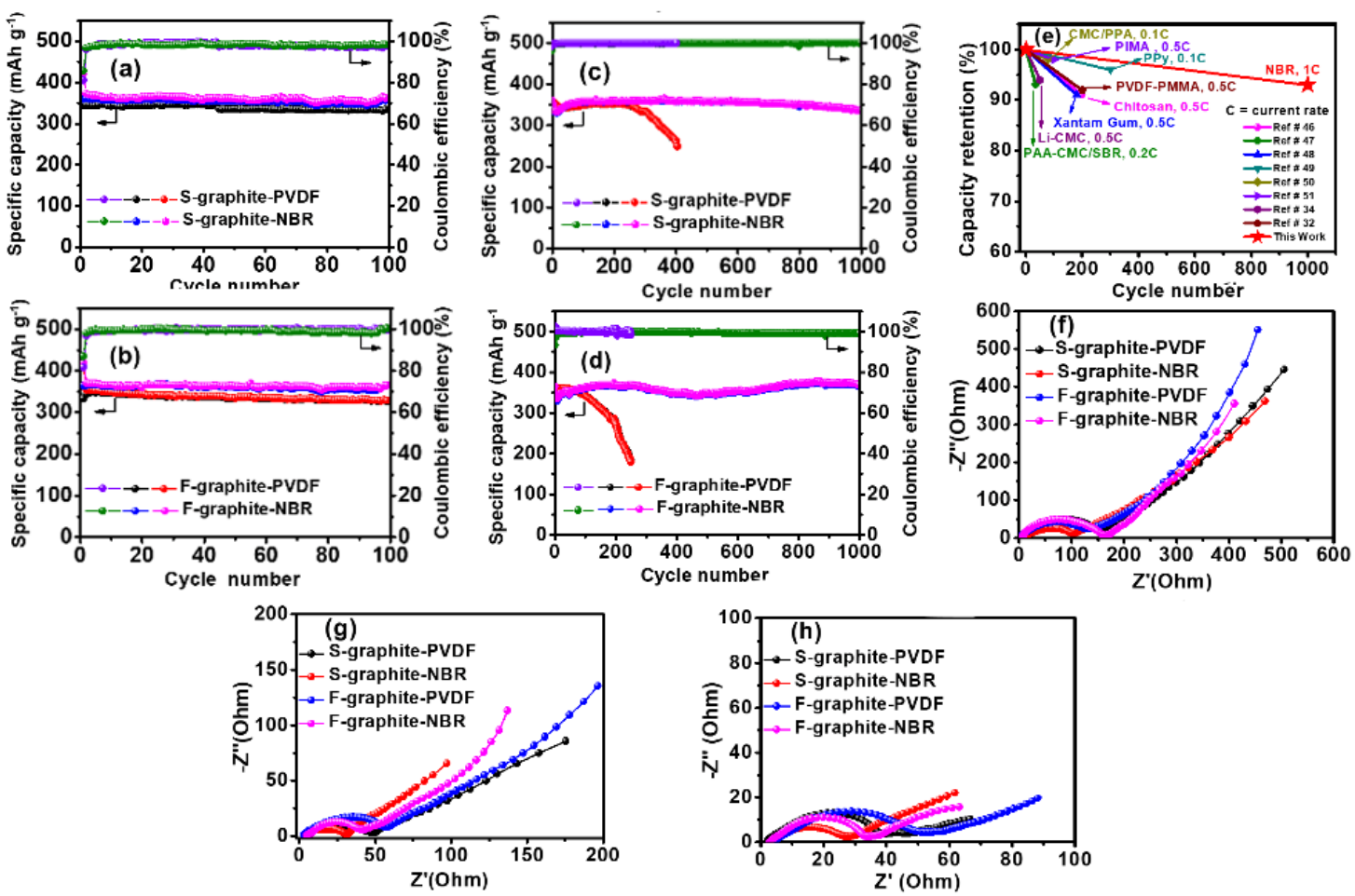

Fig. 6 The comparison in cycle performances of (a, c) S-graphite-PVDF, S-graphite-NBR and (b, d) F-graphite-PVDF, F-graphite-NBR electrodes at $0.2 C$ and $1 C$, respectively. (e) Comparison of the electrochemical performance to literature values for graphite electrodes with different binders.

Nyquist plots of all graphite electrodes using the PVDF or NBR binder. (f) Fresh electrode, (g) after first, and (h) after 100 cycles. 

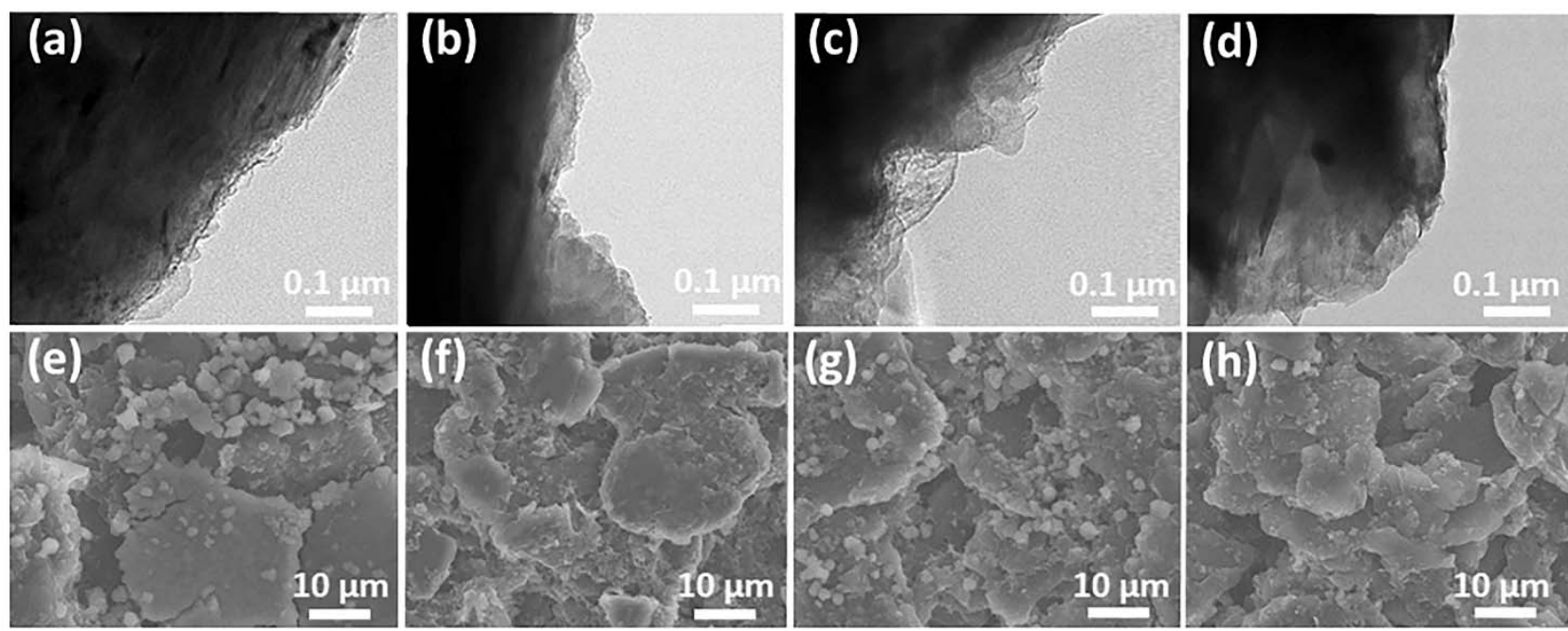

Fig. 7 TEM (a-d) and SEM (e-h) images of (a, e) S-graphite-PVDF, (b, f) S-graphite-NBR, (c, g) F-graphite-PVDF and

(d, h) F-graphite-NBR after 10 charge-discharge cycles.

in Fig. 6e $22 b, 24 b, 28 a-f$.

In order to further examine the effect of NBR binder on Li-ion diffusion in the graphite electrode, electrochemical impedance spectroscopy (EIS) measurements were conducted on the $\mathrm{Li} /$ graphite half cells at the fresh state, after the first and 100 charge-discharge cycles at a current rate of $0.2 \mathrm{C}$ as shown in Fig $6 f-h$. All Nyquist plots for the fresh cells were consisted of depressed semi-circles at high frequency and long slopes at the lower frequency region (Fig. 6f). The depressed semi-circle in the high frequency region reflects the resistance of charge transfer $(R \mathrm{ct})$ at the electrolyte/electrode interface, and the linear part appearing at the low frequency region is associated with the finite $\mathrm{Li}^{+}$diffusion in the electrodes ${ }^{29}$. Previous studies have shown that a uniformly distributed polymeric binder tightly anchored on the electrode surface can prevent the access of electrolytes to electrode surface and reduce the decomposition of electrolytes to certain degrees ${ }^{30}$. In this sense, the low impedance values of the S-graphite-NBR and F-graphite-NBR electrodes after the first and $100^{\text {th }}$ charge-discharge cycles indicate that the NBR binder is more uniformly distributed on both the basal and edge planes of graphite particles, in comparison to the PVDF. This uniform and protective coating of high amorphous NBR binder on both spherical and flaky shape graphite particles can result in a more homogeneous interfacial layer with high $\mathrm{Li}$-ion conduction. The slight decrease in $R \mathrm{ct}$ from the first cycle to the $100^{\text {th }}$ cycle demonstrates a limited growth of the solid electrolyte interphase (SEI) layer and a fast solid state $\mathrm{Li}^{+}$diffusion rate during the charge-discharge cycles in all graphite electrodes (Fig. $6 \mathrm{~g}-\mathrm{h}$ ). By comparison, the overall impedance of the graphite electrodes using the NBR binder is significantly lower than that of PVDF-based electrodes. Besides that, the steeper low frequency tail indicates the enhanced $\mathrm{Li}^{+}$ ion conductivity in the graphite electrode with NBR binder and is consistent with their electrochemical performance.

In order to better understand the effect of the NBR binder on the cycling stability and the SEI distribution of the graphite anode, all the graphite electrodes with different binders after 10 discharge-charge cycles were disassembled in argon atmosphere. The electrodes were subsequently rinsed with DMC to obliterate residual electrolyte and dried in vacuum for $6 \mathrm{~h}$ at $60^{\circ} \mathrm{C}$ before the SEM and TEM test (Fig. 7). Non-uniform passivating films associated with the SEI layers formed due to the side reactions at the electrode/electrolyte interface are clearly seen on the surface of both spherical and flaky shape graphite electrodes containing PVDF binder (Fig. 7a, c). By comparison, no discontinuity in the passivating film is observed on the entire electrode surface for spherical and flaky shape graphite electrodes with NBR binder (Fig. 7b, d). This clearly explain that the uniform distribution and good flexibility of the NBR on graphite electrodes facilitate the stable electrode/electrolyte interface and thus improve the cycle performance of the cells. Many alien particles in nanometer size were dispersed on the surface of PVDF based graphite electrodes both in spherical and flaky shape after cycling test, which should be formed by the electrolyte decomposition to form lithium carbonate (Fig. 7e, g) ${ }^{24}$. Oppositely, the NBR based graphite electrodes kept the tight structure after cycling, suggesting that the decomposition of electrolyte was suppressed by NBR modifier and stable cycle performance was achieved (Fig. 7f, h).

\section{Conclusions}

An elastomeric and amorphous NBR rubber containing abundant double bonds and nitrile groups has been investigated as the binder in Li-ion batteries for accomodating to different shapes of graphite particles. When compared to the semicrystalline PVDF binder, NBR enables to serve as a homogeneous passivation layer on both spherical and flaky graphite particles, effectively suppressing side reactions from electrolyte decomposition, and allows more uniform Li-ion diffusion at the interface. As a result, the electrochemical 
properties of both S-graphite-NBR and F-graphite-NBR electrodes are greatly improved in terms of initial C.E, reversible capacity, and cycling stability, especially at high current rate. Impressively, at high current rate of $1 C$, the S-graphite-NBR and F-graphite-NBR electrodes delivered substantially stable capacity retention up to 1000 cycles. This study signifies the importance of binder conformity to the active materials in achieving improved electrochemical performance.

Acknowledgment: We extend our sincere appreciation to the support by Suzhou Key Laboratory for Advanced Carbon Materials and Wearable Energy Technologies.

\section{References}

(1) (a) Armand, M.; Tarascon, J. M. Nature 2008, 451, 652. doi: $10.1038 / 451652 \mathrm{a}$

(b) Sun, Y.; Liu, N.; Cui, Y. Nat. Energy 2016, 1, 16071. doi: $10.1038 /$ nenergy.2016.71

(2) (a) Wang, Y. D.; Wang, J.; Mu, Q. Y.; Li, Y. W.; Qi, L. Acta Phys. -Chim. Sin. 2007, 23,14. [王雅丹, 王剑, 牟其勇, 李永伟, 其 鲁, 物理化学学报, 2007, 23, 14.] doi: 10.3866/PKU.WHXB2007Supp04

(b) Kang, B.; Ceder, G. Nature 2009, 458, 190. doi: $10.1038 /$ nature 07853

(c) Scrosati, B.; Garche, J. J. Power Sources 2010, 195, 2419. doi: 10.1016/j.jpowsour.2009.11.048

(d) Zhou, G.; Li, F.; Cheng, H. M. Energy Environ. Sci. 2014, 7, 1307. doi: 10.1039/C3EE43182G

(3) (a) Li, F.; Xu, X. Z.; Song, H.; Xiong, J.; Wu, F. Acta Phys. -Chim. Sin. 2009, 25, 2205. [李芬, 徐献芝, 宋辉, 熊晋, 吴飞, 物理化学 学报, 2009, 25, 2205.] doi: 10.3866/ PKU.WHXB20091119 (b) Yoo, M.; Frank, C. W.; Mori, S.; Yamaguchi, S. Chem. Mater. 2004, 16, 1945. doi: 10.1021/cm0304593

(c) Rago, N. D.; Bareño, J.; Li, J.; Du, Z.; Wood III, D. L.; Steele, L. A.; Lamb, J.; Spangler, S.; Grosso, C.; Fenton, K.; Bloom, I. 2018, 385, 148. J. Power Sources 2018, 385, 148. doi: 10.1016/j.jpowsour.2018.01.009

(4) Zhang, S. S.; Jow, T. R. J. Power Sources 2002, 109, 422. doi: 10.1016/S0378-7753(02)00107-6

(5) Ma, Y.; Ma, J.; Chai, J.; Liu, Z.; Ding, G.; Xu, G.; Liu, H.; Chen, B.; Zhou, X.; Cui, G.; et al. ACS Appl. Mater. Interfaces 2017, 9, 41462. doi: $10.1021 /$ acsami.7b11342

(6) (a) Zhang, S. S.; Xu, K.; Jow, T. R. J. Power Sources 2004, 138, 226. doi: 10.1016/j.jpowsour.2004.05.056

(b) Patnaik, S. G.; Vedarajan, R.; Matsumi, N. J. Mater. Chem. A 2017, 5, 17909. doi: 10.1039/C7TA03843G

(7) Komaba, S.; Shimomura, K.; Yabuuchi, N.; Ozeki, T.; Yui, H.; Komaba, S.; Shimomura, K.; Yabuuchi, N.; Ozeki, T.; Yui, H.;
Konno, K. J. Phys. Chem. C 2011, 115, 13487.

doi: 10.1021/jp201691g

(8) (a) Buqa, H.; Holzapfel, M.; Krumeich, F.; Veit, C.; Novák, P. J. Power Sources 2006, 161, 617. doi:10.1016/j.jpowsour.2006.03.073 (b) Lee, J. R.; Won, J. H.; Kim, J. H.; Kim, K. J.; Lee, S. Y. J. Power Sources 2012, 216, 42. doi: 10.1016/j.jpowsour.2012.05.052

(9) Komaba, S.; Yabuuchi, N.; Ozeki, T.; Okushi, K.; Yui, H.; Konno, K.; Katayama, Y.; Miura, T. J. Power Sources 2010, 195, 6069. doi: 10.1016/j.jpowsour.2009.12.058

(10) Lee, J. H.; Paik, U.; Hackley, V. A.; Choi, Y. M. J. Electrochem. Soc. 2005, 152, A1763. doi: 10.1149/1.1979214

(11) Tanaka, S.; Narutomi, T.; Suzuki, S.; Nakao, A.; Oji, H.; Yabuuchi, N. J. Power Sources 2017, 358, 121. doi: 10.1016/j.jpowsour.2017.05.032

(12) (a) Lee, S. Y.; Choi, Y.; Hong, K. S.; Lee, J. K.; Kim, J. Y.; Bae, J. S.; Jeong, E. D. Appl. Surf. Sci. 2018, 447, 442. doi: 10.1016/j.apsusc.2018.04.004

(b) Hays, K. A.; Ruther, R. E.; Kukay, A. J.; Cao, P. F.; Saito, T.; Wood, D. L.; Li, J. L. J. Power Sources 2018, 384, 136. doi: 10.1016/j.jpowsour.2018.02.085

(13) Qiu, L.; Shen, Y.; Fan, H.; Yang, X.; Wang, C. Int. J. Biol. Macromol. 2018, 115, 672. doi: 10.1016/j.ijbiomac.2018.04.062

(14) Lee, B. R.; Kim, S. j.; Oh, E. S. J. Electrochem. Soc. 2014, 161, A2128. doi: 10.1149/2.0641414jes

(15) Wu, Y. L.; Yang, J.; Wang, J. L.; Yin, L. C.; Nuli, Y. N. Acta Phys. -Chim. Sin. 2010, 26, 283. [伍英蕾, 杨军, 王久林, 尹利超, 努丽燕娜, 物理化学学报, 2010, 26, 283.] doi: 10.3866/PKU.WHXB20100205

(16) Kovalenko, I.; Zdyrko, B.; Magasinski, A.; Hertzberg, B.; Milicev, Z.; Burtovyy, R.; Luzinov, I.; Yushin, G. Science 2011, 334, 75. doi: $10.1126 /$ science. 1209150

(17) Bae, J.; Cha, S. H.; Park, J. Macromol. Res. 2013, 21, 826. doi: 10.1002/aenm.201100236

(18) Kim, J. S.; Choi, W.; Cho, K. Y.; Byun, D.; Lim, J.; Lee, J. K. J. Power Sources 2013, 244, 521. doi: 10.1016/j.jpowsour.2013.02.049

(19) Ma, Y.; Chen, K.; Ma, J.; Xu, G.; Dong, S.; Chen, B.; Li, J.; Chen, Z.; Zhou, X.; Cui, G. Energy Environ. Sci. 2019, 12, 273. doi: 10.1039/C8EE02555J

(20) Liu, W. R.; Yang, M. H.; Wu, H. C.; Chiao, S.; Wu, N. L. Electrochem. Solid-State Lett. 2005, 8, A100 doi: 10.1149/1.1847685

(21) Shah, R.; Gu, J.; Razzaq, A.; Zhao, X.; Shen, X.; Miao, L.; Yan, C.; Peng, Y.; Deng, Z. ACS Appl. Energy Mater. 2018, 1, 3171. doi: 10.1021/acsaem. 8 b00388

(22) (a) Wang, H.; Umeno, T.; Mizuma, K.; Yoshio, M. J. Power Sources 2008, 175, 886. doi: 10.1016/j.jpowsour.2007.09.103 (b) Rezvani, S. J.; Pasqualini, M.; Witkowska, A.; Gunnella, R.; 
Birrozzi, A.; Minicucci, M.; Rajantie, H.; Copley, M.; Nobili, F.; Di Cicco, A. Appl. Surf. Sci. 2018, 435, 1029.

doi: 10.1016/j.apsusc.2017.10.195

(c) Chou, W. Y.; Jin, Y. C.; Duh, J. G.; Lu, C. Z.; Liao, S. C. Appl. Surf. Sci. 2015, 355, 1272. doi: 10.1016/j.apsusc.2015.08.046

(23) Wang, Y.; Zheng, H.; Qu, Q.; Zhang, L.; Battaglia, VS.; Zheng, H. Carbon 2015, 92, 318. doi: 10.1016/j.carbon.2015.04.084

(24) (a) Shi, Q.; Heng, S.; Qu, Q.; Gao, T.; Liu, W.; Hang, L.; Zheng, H. J. Mater. Chem. A 2017, 22, 10885. doi: 10.1039/C7TA02706K (b) Luo, L.; Xu, Y.; Zhang, H.; Han, X.; Dong, H.; Xu, X.; Chen C.; Zhang, Y.; Lin, J. ACS Appl Mater Inter. 2016, 12, 8154. doi: 10.1021/acsami.6b03046

(25) (a) Wotango, A. S.; Su, W. N.; Haregewoin, A. M.; Chen, H. M.; Cheng, J. H.; Lin, M. H.; Wang, C. H.; Hwang, B. J. ACS Appl. Mater. Inter. 2018, 10, 25252. doi: 10.1021/acsami.8b02185 (b) Wang, Y.; Zhang, L.; Qu, Q.; Zhang, J.; Zheng, H. Electrochim. Acta 2016, 191, 70. doi: 10.1016/j.electacta.2016.01.025

(26) (a) Xiang, H.; Mei, D.; Yan, P.; Bhattacharya, P.; Burton, S. D.; von Wald Cresce, A.; Cao, R.; Engelhard, M. H.; Bowden, M. E.; Zhu, Z.; et al. ACS Appl. Mater. Interfaces 2015, 7, 20687.

doi: 10.1021/acsami.5b05552

(b) Kil, K. C. Paik, U. Macromol. Res. 2015, 23, 719. doi: 10.1007/s13233-015-3094-1

(27) (a) Wang, R.; Feng, L.; Yang, W.; Zhang, Y.; Zhang, Y.; Bai, W.; Liu, B.; Zhang, W.; Chuan, Y.; Zheng, Z. Nanoscale Res. Lett. 2017, 12, 575. doi: 10.1186/s11671-017-2348-6

(b) Komaba, S.; Itabashi, T.; Kaplan, B.; Groult, H.; Kumagai, N. Electrochem. Commun. 2003, 5, 962. doi: 10.1016/j.e;ecom.2003.09.003 (c) Lee, J. T.; Wu, M. S.; Wang, F. M.; Lin, Y. W.; Bai, M. Y.;
Chiang, P. C. J. J. Electrochem. Soc. 2005, 152, A1837. doi: $10.1149 / 1.1993407$

(28) (a) Chai, L.; Qu, Q.; Zhang, L.; Shen, M.; Zhang, L.; Zheng, H. Electrochim. Acta 2013, 105, 378. doi: 10.1016/j.electacta.2013.05.009

(b) Wang, Z.; Dang, G.; Zhang, Q.; Xie, J. Inter. J. Electrochem. Sci. 2017, 12, 7457. doi: 10.20964/2017.08.55

(c) Zhao, H.; Du, A.; Ling, M.; Battaglia, V.; Liu, G. Electrochim. Acta 2016, 209, 159. doi: 10.1016/j.electacta.2016.05.061

(d) Gómez-Cámer, J. L.; Bünzli, C.; Hantel, M. M.; Poux, T.; Novák, P. Carbon 2016, 105, 42. doi: 10.1016/j.carbon.2016.04.022

(e) Ku, J. H.; Hwang, S. S.; Ham, D. J.; Song, M. S.; Shon, J. K.; Ji, S. M.; Choi, J. M.; Doo, S. G. J. Power Sources 2015, 287, 36. doi: 10.1016/j.jpowsour.2015.04.007

(f) Shin, D.; Park, H.; Paik, U. Electrochem. Commun. 2017, 77, 103 doi: 10.1016/j.elecom.2017.02.018

(29) (a) Tang, J.; Yang, J.; Zhou, X.; Yao, H.; Zhou, L. J. Mater. Chem. A 2015, 3, 23844. doi: 10.1039/C5TA06859B

(b) Levi, M. D.; Aurbach, D. J. Phys. Chem. B 1997, 101, 4630. doi: 10.1021/jp9701909

(c) Sun, X. Z.; Huang, B.; Zhang, X.; Zhang, D. C.; Zhang, H. T.; Ma, Y. W. Acta Phys. -Chim. Sin. 2014, 30, 2071. [孙现众, 黄博, 张熊, 张大成, 张海涛, 马衍伟. 物理化学学报, 2014, 30, 2071.] doi: 10.3866/PKU.WHXB201408292

(30) (a) Zhang, L.; Zhang, L.; Chai, L.; Xue, P.; Hao, W.; Zheng, H. J. Mater. Chem. A 2014, 2, 19036. doi: 10.1039/C4TA04320K (b) Ryou, M. H.; Kim, J.; Lee, I.; Kim, S.; Jeong, Y.; K.; Hong, S.; Ryu, J. H.; Kim, T. S.; Park, J. K.; Lee, H. Adv. Mater. 2013, 25, 1571. doi: 1010.1002/adma.201203981 